\title{
Research Paper \\ The Effect of 6-Week Pilates Exercise and Fenugreek Supplement on Total Anti- oxidant Capacity and Mineral Content in Active Women
}

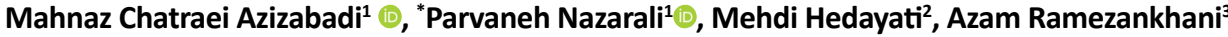

1. Department of Exercise Physiology, Faculty of Physical Education, Alzahra University, Tehran, Iran.

2. Research Institute for Endocrine Science, Shahid Beheshti University of Medical Sciences, Tehran, Iran.

3. Department of Exercise Physiology, Faculty of Physical Education and Sport Sciences, Tehran University, Tehran, Iran.

\begin{tabular}{|c|c|}
\hline $\begin{array}{l}\text { Use your device to scan } \\
\text { and read the article online }\end{array}$ & CFtation Chatraei Azizabadi M, NazarAli P, Hedayati M, Ramezankhani A. [The Effect of 6-Week of Pilates Training With Fenu- \\
\hline 口ifing & $\begin{array}{l}\text { greek Supplementation on Total Antioxidant Capacity and Minerals in Active Women (Persian)]. Quarterly of "The Horizon of } \\
\text { Medical Sciences". 2019; 25(3):158-172. https://doi.org/10.32598/hms.25.3.158 }\end{array}$ \\
\hline 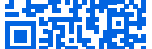 & dolinttps://doi.org/10.32598/hms.25.3.158 \\
\hline
\end{tabular}

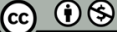

Received: 23 Nov 2018 Accepted: 14 May 2019 Available Online: 01 Jul 2019

Key words: Antioxidants, Pilates, Active woman, Fenugreek, Mineral

\section{ABSTRACT}

Aims Certain exercises can develop the antioxidant system. Fenugreek supplementation containing antioxidant capacity and minerals may increase the benefits of exercises. The current study aimed at investigating the effect of Pilates training with fenugreek supplement on Total Antioxidant Capacity (TAC) and minerals in active women.

Methods \& Materials The current study was with a quasi-experimental design was conducted on 36 active women aged 21-28 years randomly assigned into four groups: training, supplement, training plus supplement, and control. The training groups performed six weeks of Pilates training with the intensity of $60 \%-80 \%$ of maximal heart rate, three times a week for six weeks. Supplement groups received 500 mg fenugreek seeds daily for six weeks. Before and after the intervention, TAC and minerals (calcium, phosphorus, and iron) were measured. Data were analyzed by two-way ANOVA, Tukey post hoc test, and paired t-test at significant levels of $\mathrm{P}<0.05$

Findings In two variables, TAC and calcium, the time effect was significant, in other words, regardless of the group factor, there were significant differences between the post-test and pre-test of TAC and calcium variables in the experimental groups. The interaction of time-group was significant in TAC variable $(P<0.05)$. The effect of the group was not significant in any of the variables.

Conclusion The obtained results suggested that one period of Pilates training and the use of fenugreek supplement alone and in combination could possibly prevent oxidative stress induced by exercise and could be effective in enhancing TAC and increasing calcium levels in active women.

\section{Extended Abstract}

\section{Introduction}

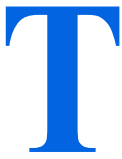

he antioxidant system can be improved as a result of some exercises. Fenugreek herbal supplement also has antioxidant property and mineral contents that can increase the benefits of exercises. It is likely that the antioxidant system can be more improved by combining exercises with fenugreek supplement. It is also possible to increase the level of minerals that athletes require by taking fenugreek supplement rich in minerals.

* Corresponding Author:

Parvaneh Nazarali, PhD.

Address: Department of Exercise Physiology, Faculty of Educational Sciences and Psychology, Alzahra University, Tehran, Iran

Tel: +98 (21) 88041468

E-mail: parvaneh_nazarali@yahoo.com 


\section{Methods}

Davis et al. in 1982 were the first to report that exercise results in producing free radicals. Aerobic activities are associated with increased oxygen consumption and can lead to increased production of free radicals [1]. Studies show that regular physical activity increases the capability of the antioxidant system of the body and protects it against the destructive properties of oxidative stress resulting from increased exercise. These changes occur over time and in parallel with other adaptations of exercise. Regular exercise creates some adaptation in the antioxidant system which increases resistance to oxidative stress $[4,5]$.

Some studies are conducted on the effect of using medicinal plants combined with exercise on the antioxidant status of the body. Medicinal plants contain large amounts of antioxidants that can inhibit free radicals. Antioxidant compounds of these plants belong to phenolic compounds such as phenolic acids, flavonoids, tocopherols, and a group of carotenoids [7]. A few studies are also conducted on the various properties of fenugreek and its therapeutic effects on various reported cases, but its effects on the antioxidant level of human samples are not investigated yet [9]; moreover, the effects of using fenugreek supplementation and exercise simultaneously on antioxidant properties are not studied yet [4].

Aim

The current study aimed at evaluating the effect of a Pilates training course with fenugreek supplementation on Total Antioxidant Capacity (TAC) and minerals of active women.

\section{Study design, population, and sample}

The current quasi-experimental study with Pre-test-Posttest design was conducted in 2018 on all active and healthy female students aged 21-28 years in Tehran. Of these, 36 students were selected through announcements and on a voluntary basis with regard to the inclusion criteria. These criteria included: having regular exercise (regular physical activity two days a week and at least 2 years of regular exercise), no joint diseases and bone fractures in the past year, not smoking, no supplementary dietary, and no diseases affecting the results. The samples were randomly divided into four groups: Exercise (EX), Supplement (SUP), exercise plus supplement (EX+SUP), and control (Table 1).

\section{Measures}

The body-weight of subjects was measured wearing light clothes and no shoes using an analog scale (Beurer, Ger- many) with an accuracy of $0.1 \mathrm{~kg}$, and their height was measured in standing position without shoes and shoulders and heels touching the wall using a wall mount stadiometer (Seca, China) with an accuracy of $0.1 \mathrm{~cm}$. Their Body Mass Index (BMI) was obtained by dividing the weight in kilograms by the square of the height in meters. During the six-week study period, SUP group received 500 $\mathrm{mg}$ of fenugreek powder once a day after dinner [12]. The powdered fenugreek seeds were put into 600-mg gelatin capsule shells in a chemistry lab with a digital scale with an accuracy of $0.001 \mathrm{~g}$. The subjects were asked to refrain from taking any medication during the study. The control group consumed a placebo drug (starch). For the EX group, the Pilates exercise protocol was assigned for six weeks, three sessions per week, and each for 60 minutes.

Pilates exercises included simple movements involving most of the trunk muscles (transverse abdominal muscles, internal and external oblique muscle, diaphragm, quadriceps, iliopsoas muscle, spinal extensors, and buttocks) and were performed in three positions of standing, sitting, and supine with no need to any specific equipment. The exercises started with low intensity and gradually increased every week [6]. To keep the principle of overload, new exercises were added in each session. In the first session, the intensity of exercise, measured with a Polar wristwatch, was about $60 \%-70 \%$ of the maximum heart rate. Over the next two weeks, the rate reached $70-75 \%$ and in the end sessions reached $75 \%-80 \%$ of the maximum heart rate. Blood samples were taken from subjects before the intervention and 48 hours after the last training session.

The studied blood factors were TAC and the level of minerals (calcium, phosphorus, magnesium, and iron). The TAC was measured using colorimetric oxidation-reduction method with a sensitivity of $0.1 \mathrm{~mm}$; calcium was measured by photometric test using Cresolphthalein Complexone (CPC) with a sensitivity of $0.2 \mathrm{mg} / \mathrm{dL}$; magnesium by photometric test (endpoint method) using xylidyl blue with a sensitivity of $0.5 \mathrm{mg} / \mathrm{dL}$; iron by photometric test with a sensitivity of $0.2 \mathrm{mg} / \mathrm{dL}$; and phosphorus by photometric and ultraviolet test with a sensitivity of $0.7 \mathrm{mg} / \mathrm{dL}$. Collected data, after coding, were analyzed in SPSS V. 20 software. Shapiro-Wilk statistical test was used to examine the normality of data distribution. For analyzing data, two-way ANOVA (Table 2), Tukey post hoc test and paired t-test were used. The significance level was set at $0.05(\mathrm{P}<0.05)$ (Table 3$)$.

\section{Results}

ANOVA results for the variables of TAC, calcium level, phosphorus level, and iron level are presented in Table 2. Of TAC, results showed that the effect of time and the interaction 
Table 1. Mean $\pm S D$ of Participants' Characteristics

\begin{tabular}{ccccc}
\hline \multirow{2}{*}{ Characteristics } & \multicolumn{5}{c}{ Mean \pm SD } \\
\cline { 2 - 5 } & EX & SUP & EX+SUP & Control \\
\hline Number & 9 & 9 & 9 & 9 \\
Age & $24.52 \pm 6.08$ & $25.11 \pm 5.13$ & $24.83 \pm 6.25$ & $26.01 \pm 4.93$ \\
Weight $(\mathrm{kg})$ & $59.11 \pm 5.46$ & $63.28 \pm 508$ & $59.88 \pm 5.70$ & $65.55 \pm 5.22$ \\
Height $(\mathrm{cm})$ & $163.65 \pm 5.46$ & $167.54 \pm 5.08$ & $165.55 \pm 5.70$ & $164.66 \pm 5.22$ \\
BMI $\left(\mathrm{kg} / \mathrm{m}^{2}\right)$ & $22.24 \pm 1.48$ & $22.68 \pm 1.02$ & $99.21 \pm 1.22$ & $21.20 \pm 1.15$ \\
\hline
\end{tabular}

Table 2. Two-way ANOVA Results for TAC and Levels of Calcium, Phosphorus, and Iron $\quad \begin{aligned} & \text { Quarterly of } \\ & \text { The Horizon of Medical Sciences }\end{aligned}$

\begin{tabular}{|c|c|c|c|c|}
\hline Variable & Source & Mean squares & $\mathbf{F}$ & p \\
\hline \multirow{3}{*}{$\mathrm{TAC}(\mathrm{mM})$} & Time & 0.011 & 31.124 & $0.001 *$ \\
\hline & Group & 0.002 & 0.291 & 0.831 \\
\hline & Time $\times$ group & 0.007 & 6.354 & $0.002^{*}$ \\
\hline \multirow{3}{*}{ Calcium (mg/dL) } & Time & 2.205 & 20.334 & $0.001 *$ \\
\hline & Group & 0.278 & 1.933 & 0.144 \\
\hline & Time $\times$ group & 0.242 & 2.229 & 0.104 \\
\hline \multirow{3}{*}{$\operatorname{Iron}(\mu \mathrm{g} / \mathrm{dL})$} & Time & 7.540 & 0.019 & 0.892 \\
\hline & Group & 381.947 & 0.223 & 0.880 \\
\hline & Time $\times$ group & 313.819 & 0.778 & 0.515 \\
\hline \multirow{3}{*}{ Phosphorus (mg/dL) } & Time & 0.036 & 0.304 & 0.585 \\
\hline & Group & 0.737 & 2.202 & 0.107 \\
\hline & Time $\times$ group & 0.049 & 0.422 & 0.739 \\
\hline
\end{tabular}

Table 3. Paired t-test results of variables

The Horizon of Medical Sciences

\begin{tabular}{|c|c|c|c|c|}
\hline Variable & Group & Post-test & Pre-test & $\mathbf{P}$ \\
\hline \multirow{4}{*}{$\mathrm{TAC}(\mathrm{mM})$} & EX & $0.0 \pm 32.05$ & $0.1 \pm 35.05$ & $0.012 *$ \\
\hline & SUP & $0.0 \pm 33.05$ & $0.0 \pm 37.06$ & $0.001 *$ \\
\hline & $E X+S U P$ & $0.0 \pm 33.04$ & $0.1 \pm 36.06$ & $0.001^{*}$ \\
\hline & Control & $0.0 \pm 33.06$ & $0.0 \pm 32.05$ & 0.496 \\
\hline \multirow{4}{*}{ Calcium (mg/dL) } & EX & $9 \pm 46.45$ & $9 \pm 72.49$ & $0.029 *$ \\
\hline & SUP & $8 \pm 98.36$ & $9 \pm 38.35$ & $0.002^{*}$ \\
\hline & $E X+S U P$ & $9 \pm 6.38$ & $9 \pm 46.30$ & $0.001^{*}$ \\
\hline & Control & $9 \pm 13.38$ & $9 \pm 15.47$ & 0.14 \\
\hline \multirow{4}{*}{$\operatorname{Iron}(\mu \mathrm{g} / \mathrm{dL})$} & EX & $93.29 \pm 87.77$ & $89.23 \pm 88.38$ & 0.571 \\
\hline & SUP & $95.41 \pm 44.23$ & $88.30 \pm 55.99$ & 0.475 \\
\hline & $E X+S U P$ & $86.33 \pm 77.77$ & $98.31 \pm 44.52$ & 0.187 \\
\hline & Control & $100.3 \pm 82.20$ & $100.34 \pm 88.87$ & 0.994 \\
\hline \multirow{4}{*}{ Phosphorus (mg/dL) } & EX & $3 \pm 87.44$ & $3 \pm 92.62$ & 0.760 \\
\hline & SUP & $4 \pm 27.50$ & $4 \pm 33.52$ & 0.567 \\
\hline & EX+SUP & $4 \pm 31.64$ & $4 \pm 24.5$ & 0.567 \\
\hline & Control & $3 \pm 90.47$ & $4 \pm 00.46$ & 0.063 \\
\hline
\end{tabular}


effect between group and time was significant but the group had no significant effect on TAC. Paired t-test results reported that in the Post-test phase, the TAC increased significantly in all experimental groups (EX, SUP and EX + SUP) compared to the Pre-test phase $(\mathrm{P}<0.05)$. The results of the Tukey post hoc test and pairwise comparisons showed no significant difference among the experimental groups in terms of TAC changes. Regarding calcium level, only the effect of time was significant. A significant difference was observed between the Post-test and the Pre-test calcium levels. Paired t-test results showed that in all experimental and control groups, calcium level increased significantly after the intervention compared to the Pre-test scores $(\mathrm{P}<0.05)$. Regarding phosphorus and iron levels, effects of time, group, and time-group were not significant. In all groups, iron and phosphorus did not change significantly and there was no significant difference between calcium, phosphorus, and iron levels in all groups $(\mathrm{P}>0.05)$.

\section{Discussion}

Regarding the effect of exercise on TAC, results of the current study were in agreement with those of some other studies $[13,14]$ while they were inconsistent with those of some others $[15,16]$. Nakhaee et al. [17] in their study reported the increased TAC after a six-week aerobic training with 60$80 \% \mathrm{VO} 2$ max intensity in active women, while Jahani et al. reported that TAC levels decreased significantly after eight weeks of continuous and regular exercise in soccer players [18]. Kumar et al. in a study evaluated antioxidant and antifatigue properties of fenugreek in rats subjected to weight loaded forced swim test, and concluded that fenugreek hydroalcoholic extract reduces free radicals and increases the activity of antioxidant enzymes [21]. The study by Adibi et al. also showed that endurance training and fenugreek supplementation in male diabetic rats can improve their plasma antioxidants, but their simultaneous use results in synergistic effects and strengthens the antioxidant system [22].

In a study, it was observed that the serum iron level enhanced in rats fed by wheat biscuit supplemented by fenugreek seed flour [24]. Regarding the results for serum phosphorus level, the results of Al-Sultan and El-Bahr were similar to those of the current study [26]. They found no significant difference in serum phosphorus level of rats using aqueous extract of fenugreek. However, the current study results were not consistent with those of Townsend et al. and Tartibian et al. where no significant change in serum calcium levels was reported [28-30]. The current study showed that six-week Pilates training resulted in a slight decrease in serum iron level but this effect was not statistically significant, which was consistent with the results of Inoue et al. and Ka- basakalis et al. but contrary to the findings of Liu et al. Goto et al. and Alikarami et al. [33-37].

To obtain more conclusive results the effect of fenugreek supplementation on the TAC and levels of minerals, further studies with more careful control and data collection, larger sample size, or different doses of fenugreek are recommended. The present study had some limitations such as lack of the supervision of the physical activity of participants at the time out of study and lack of precise control of their nutritional status.

\section{Conclusion}

A Pilates exercise course alone or in combination with fenugreek supplementation may significantly increase TAC and calcium level in active women aged 21-28 years. The combined effects of supplementation and Pilates training had no synergistic effect on improving antioxidant status.

\section{Ethical Considerations}

\section{Compliance with ethical guidelines}

This study obtained its ethical clearance from the Ethics Committee of Alzahra University. All ethical principles were in accordance with the Declaration of Helsinki.

\section{Funding}

This article is extracted from a master thesis authored by Mahnaz Chetraei Azizabadi with the approval code of 2401026 obtained from the Department of Exercise Physiology, Faculty of Physical Education and Sport Sciences, Alzahra University.

\section{Authors' contributions}

All authors contributed in preparing this article.

\section{Conflicts of interest}

The authors declare no conflict of interests. 
This Page Intentionally Left Blank 


\title{
تأثير شش هفته تمرين ييلاتس و مكملدهى شنبليله بر ظرفيت تام ضداكسايشى و مواد معدنى

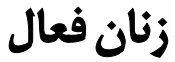

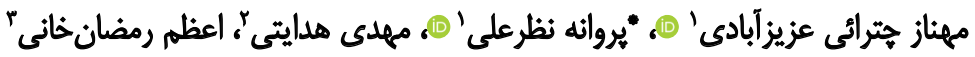

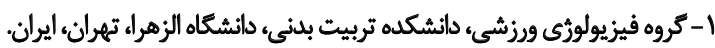

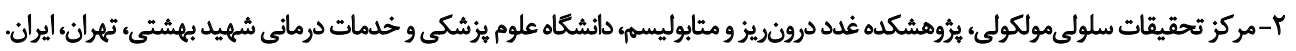

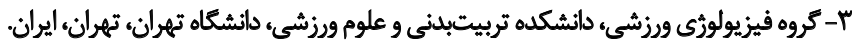

\begin{abstract}
حكSי

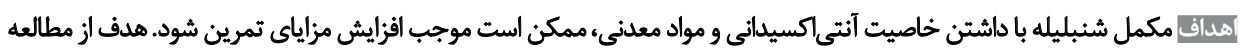

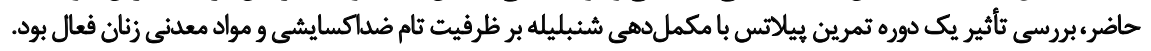

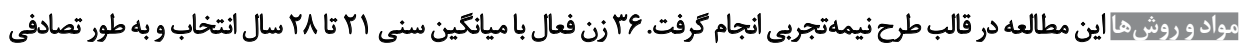

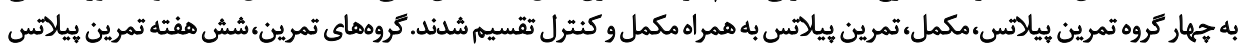

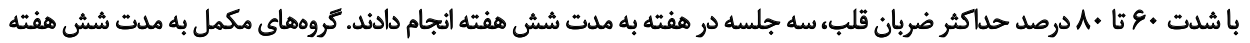

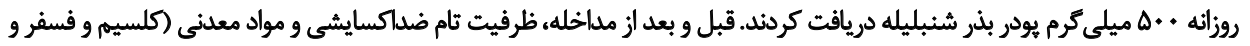

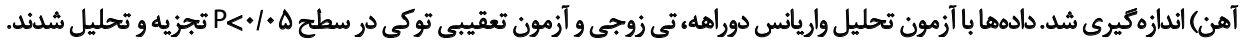

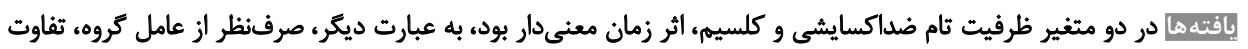

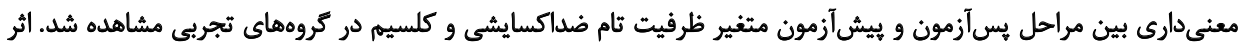

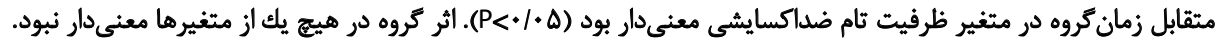

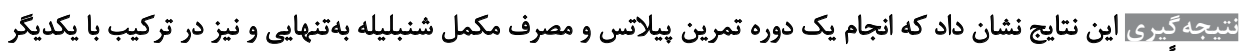

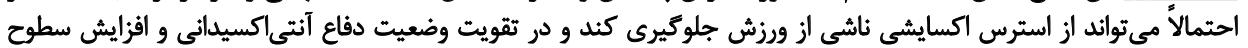

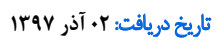

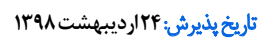

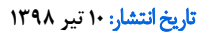

كليدواؤها: آنتىاكسيدان، بيلاتس، زنان فعال، شنبليله،

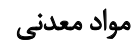

ضداكسايشى اولين خط دفاعى در برابر حمله انواع راديكالهاي

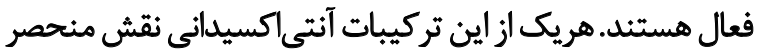

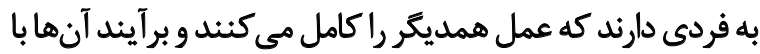

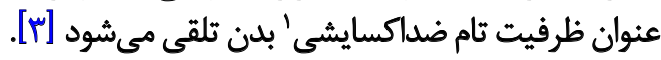

تمرينهاى منظم بدنى توانايى سيستمهاى ضداكسايشى بلدن

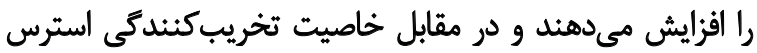

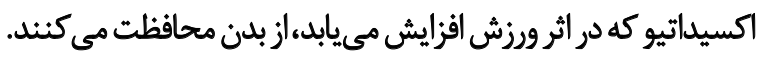

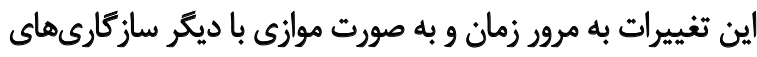

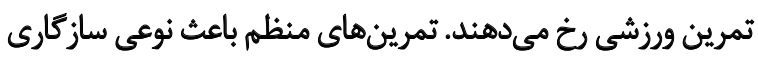

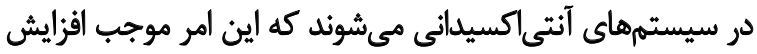

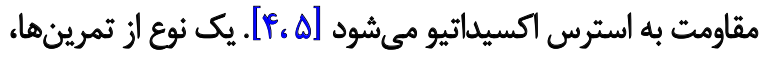

\section{TAC}

doleso

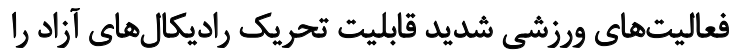

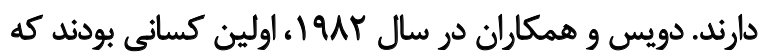

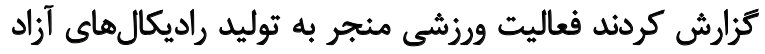

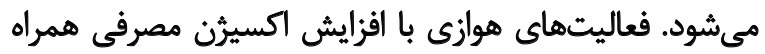

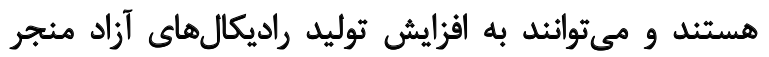

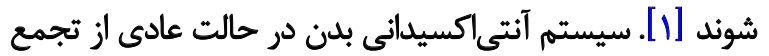

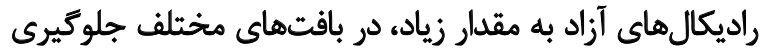

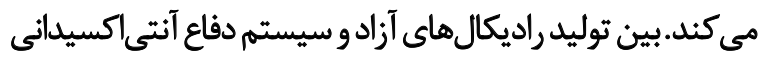

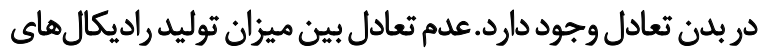

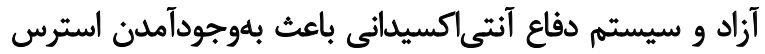

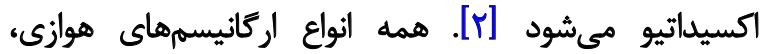
عليه كونههاي فعال اكسيرن سيستم دفاعى دارند. آنزيمهائ هواني 


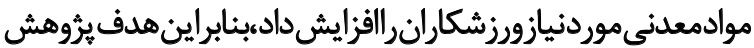

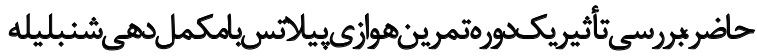
برظرفيت ثام ضداكسايشى و سطح مواد معدنى زنان فعال است

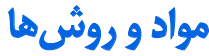

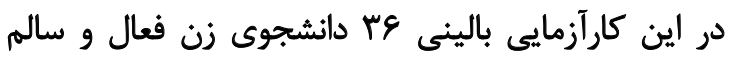

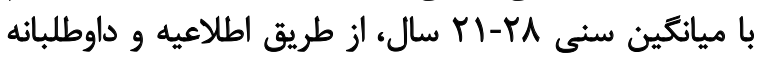

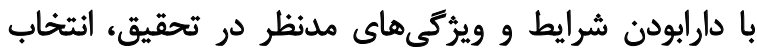

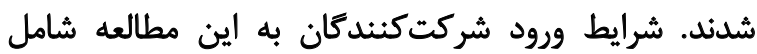

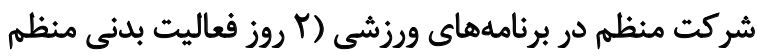

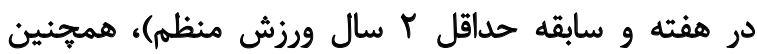

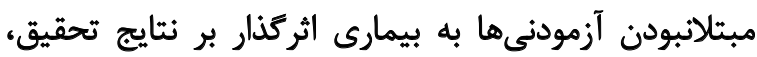

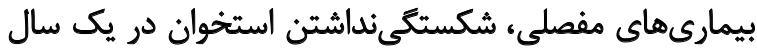

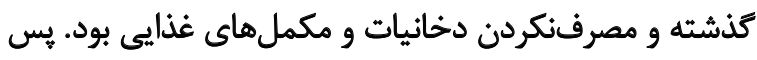

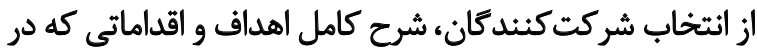

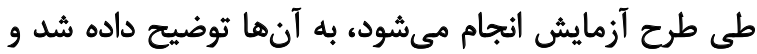

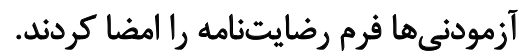

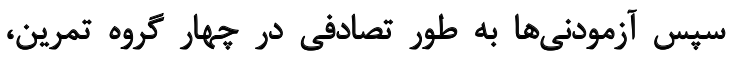

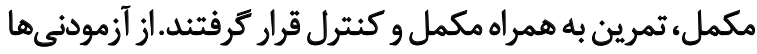

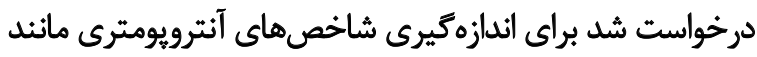

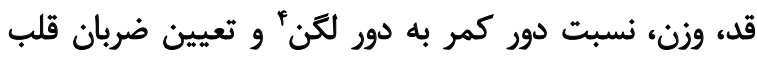

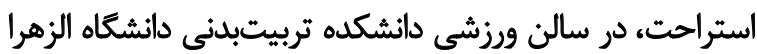

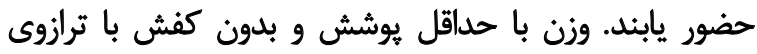

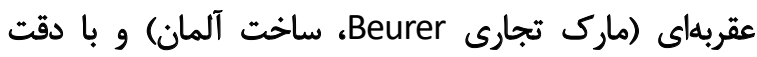

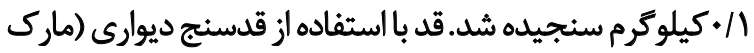

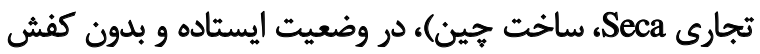

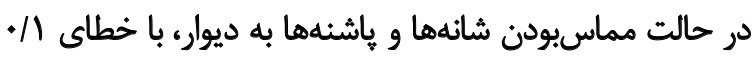

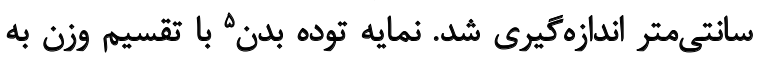

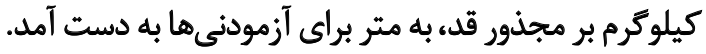
در طول شش هفته دوره تحقيق، كروههاى مكمل يك بار در روز

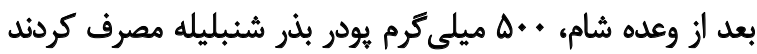

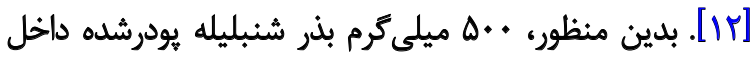

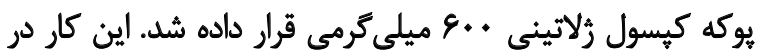

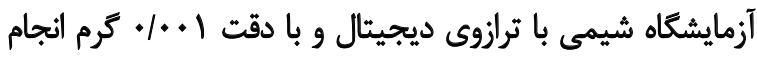

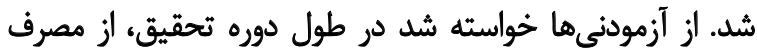

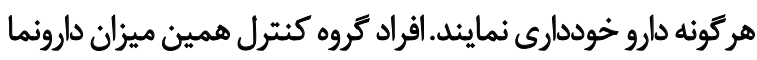

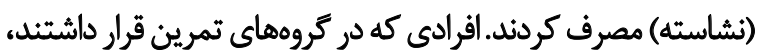

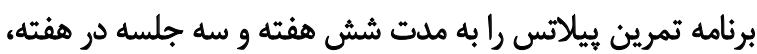
هر جلسه به مدت •و دقيقه انجام دادند.

تمرينهاى بيلاتس،شامل حركات سادهاى است كه بيشتر عضلات
فعاليت ورزشى بيلاتس باست. تمرين بيلاتس، شامل حركاتى است

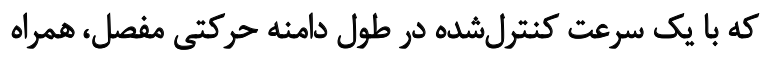

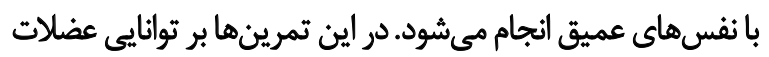

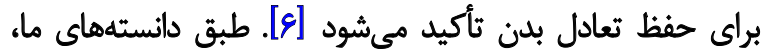

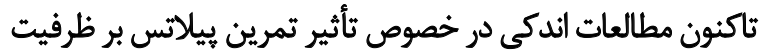
ت تام ضداكسايشى انجام شده است.

در كنار اين يرؤهشها، مطالعاتى در رابطه با بهكاركيرى

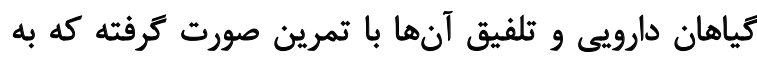

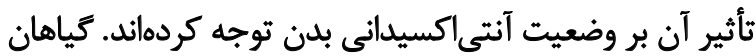

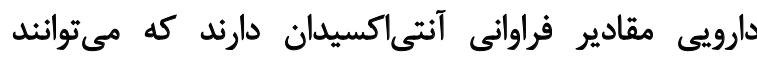

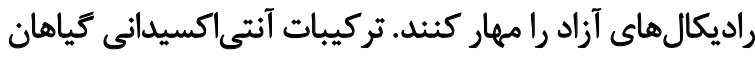

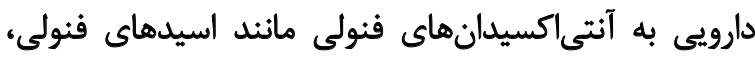

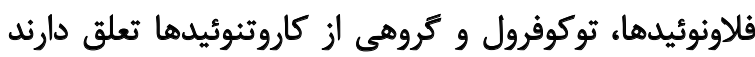

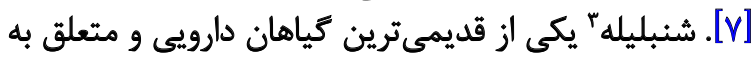

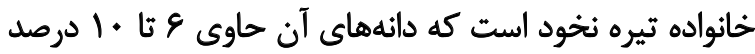

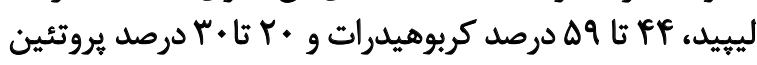

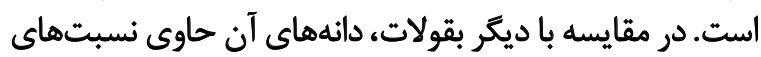

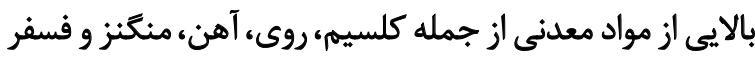

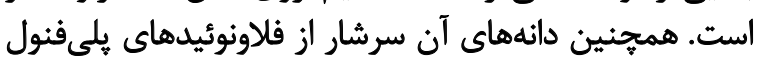

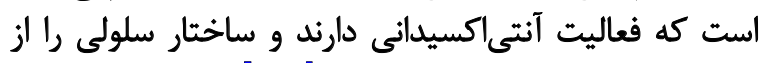

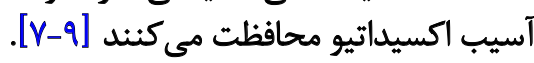

به علت طعم معطر، از كياهانى است كه برك هاو و دانهايش

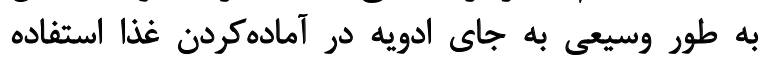

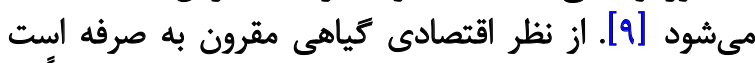

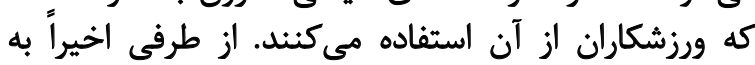

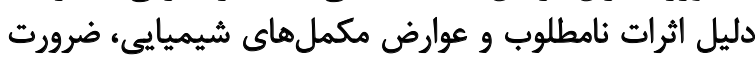

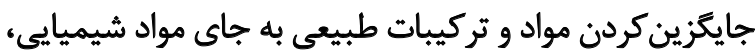

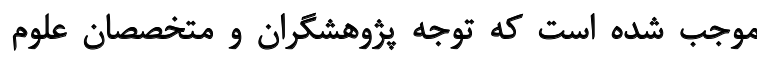

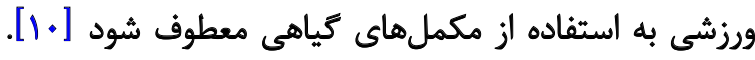

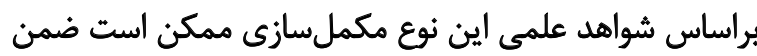

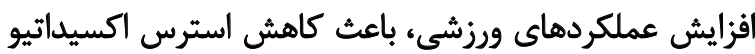
ناشى از انجام فعاليت ورزشى شودي شود [11]. مطالعاتى در زمينه خواص كوناكون كياه شنبليله انجام و اثرات

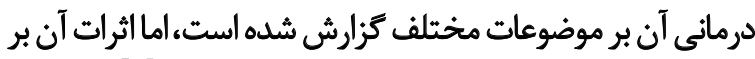

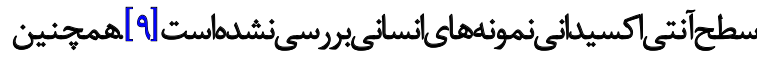

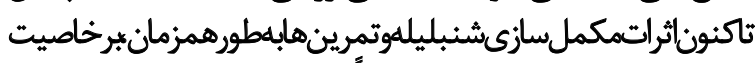

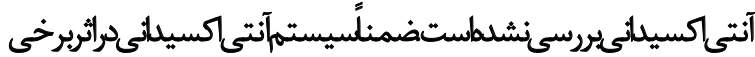

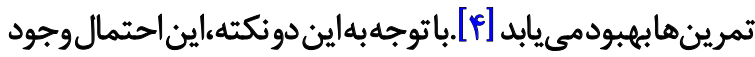

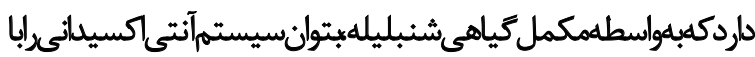

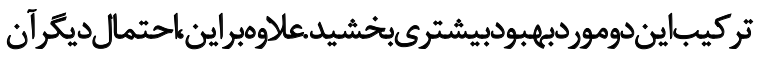

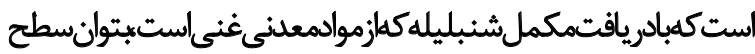

2. Pilates

3. Trigonella foenum graecum 
زوجى استفاده شد. در همه آزمونها، مقدار خطا در سطح

Pحاسبه شد. $P<1 \cdot 0$

Latiols

ويزگى هاى دموكرافيك آزمودنى ها در جدول شماره لا آورده شده است. قبل از آزمون فرضيهماي تحقيق، طبيعى بودن توزيع دادهها

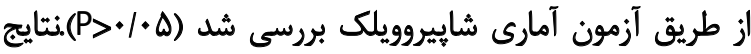

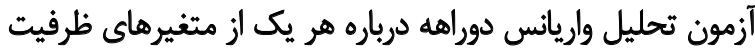

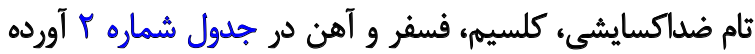

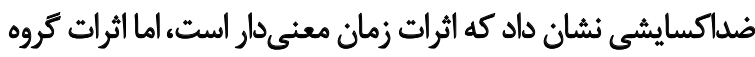

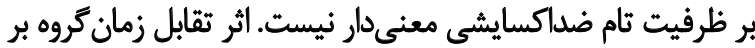

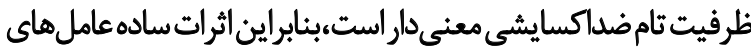

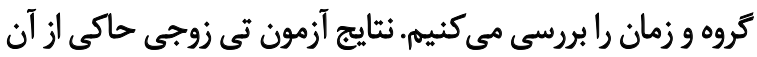

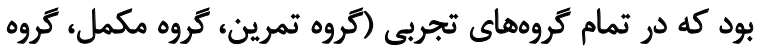

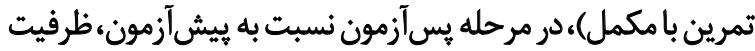

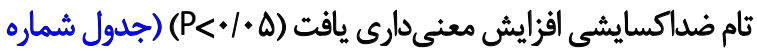

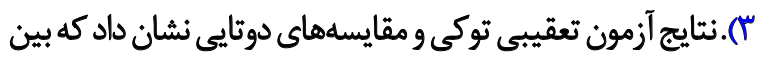

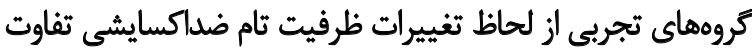

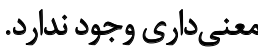

درباره متغير كلسيه، اثرات زمان معنى دار است، به عبارت ديخر

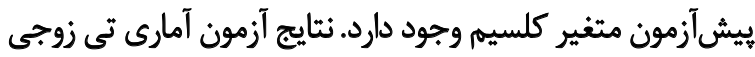

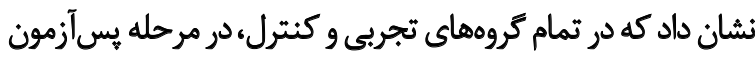

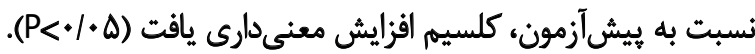

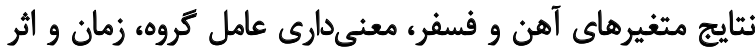

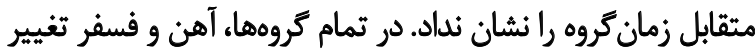

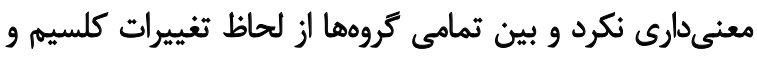

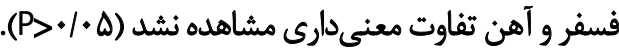

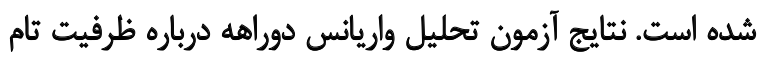

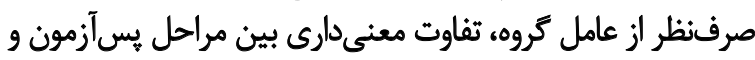

تنه (عرضي شكمي، مايل داخلي، خارجي، ديافراكم، مربع كمرى،

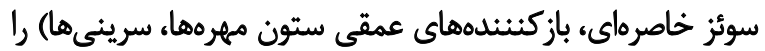

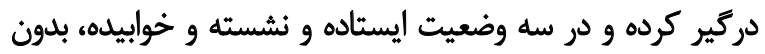

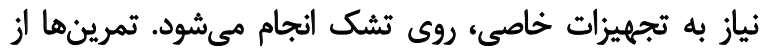

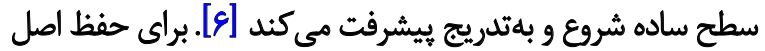

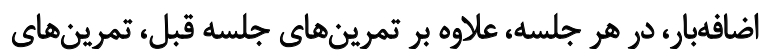

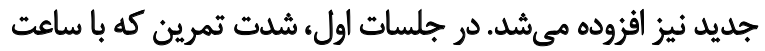

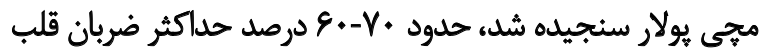

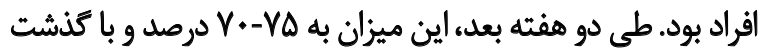

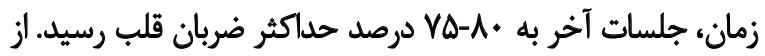

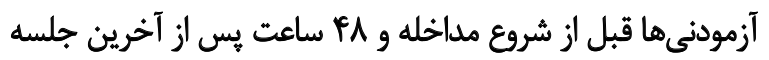
تمريني، خون كرفته شد. فاكتورهاي خوني بروسي مداخده

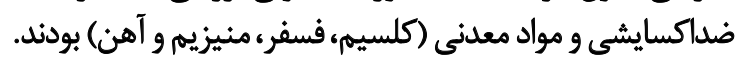
ظرفيت ثام ضداكسايشى بر اساس آزمون رنغسينجى كاهش

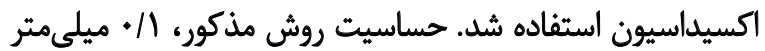

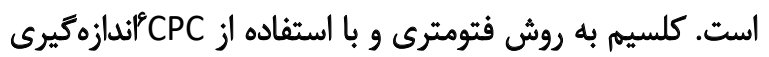

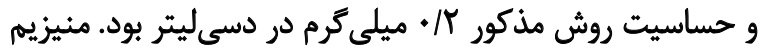

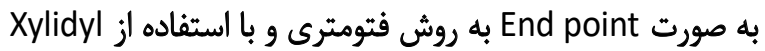

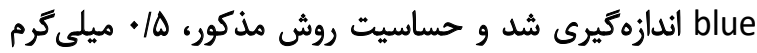

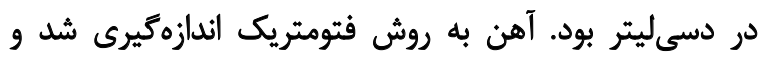

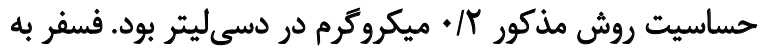

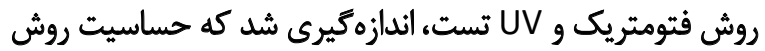
مذكور، V/ • ميلى مترم در دسى ليتر بود.

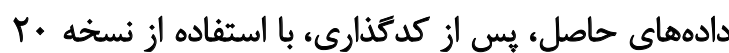

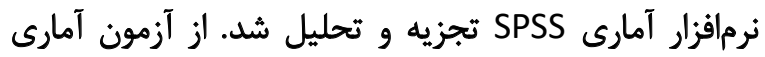

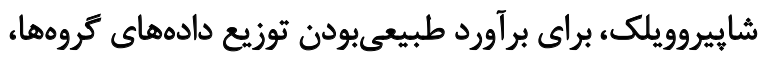

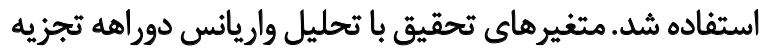

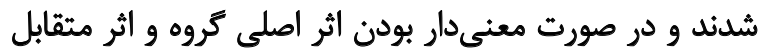
(كروهزمان) از آزمون تعقيبى توكى براي مقايسه استفاده شد. در صورت معنى داربودن اثر اصلى زمان، از آزمون تمونى آمارى تى تى

6. Cresolphethalein copmplexone

جدول ا. مشخصات جمعيتشناختى آزمودنى هاى يروهش به تفكيك جهار كروه

\begin{tabular}{|c|c|c|c|c|}
\hline \multicolumn{4}{|c|}{ ميائكين ثلانحراف معيار (كروه) } & \multirow[t]{2}{*}{ متغير } \\
\hline كتترل & تمرين با مكمل & مكمل & تمرين & \\
\hline 9 & 9 & 9 & 9 & تعداد \\
\hline$r q /+1 \pm r / q r$ & $\Gamma F / A r \pm \& / T \Delta$ & $r \Delta / / 1 \pm \Delta / / r$ & $M \varphi / \Delta r \pm \& /+1$ & سن (سال) \\
\hline$\Delta S / \Delta \omega \pm \Delta / \pi r$ & $\Delta Q / M \pm \Delta / V$ & $Q T / r \Lambda \pm \Delta / \bullet \Lambda$ & $\Delta q / 11 \pm \Delta / \& \varepsilon$ & ونن (كيلوكرم) \\
\hline $\mid g T / g g \pm \Delta / M T$ & $\mid F \Delta / \Delta \Delta \pm \Delta / V$ & $\mid \varnothing V / \Delta F \pm \Delta / \cdot \Lambda$ & $\mid \varepsilon r / \& \Delta \pm \Delta / \digamma \varepsilon$ & قدل (سانتىمتر) \\
\hline$r V / \cdot r \pm V / / \Delta$ & $r / 99 \pm 1 / T r$ & rr/gA $\pm 1 / \cdot r$ & $M r / M e \pm 1 / T A$ & نمايه توده بدثي (kg/m \\
\hline
\end{tabular}


جدول ب. نتايج آزمون تحليل واريانس دوراهه درباره متغيرهاى ظرفيت تام ضداكسايشى، كلسيه، آهن و فسفر

\begin{tabular}{|c|c|c|c|c|}
\hline$P$ & الرزش F & ميانغين مجذورات & منبع تغيير & مثتير \\
\hline $.1 *+1 *$ & MI/Irf & .1 .11 & ائر زمان & \\
\hline +|Ar| &.$/ 491$ & 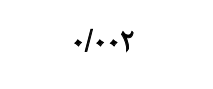 & اثر كروه & ضاكسايشي) ضرفيت تام \\
\hline$\cdot 1 \cdot+r^{*}$ & g/THF & $.1 \cdot \cdot v$ & تعامل كروهزمان & \\
\hline $.10 .1^{*}$ & $r \cdot / m e$ & $T / Y \cdot \Delta$ & ائر زمان & \\
\hline . Mff & 1/9m &.$/ \mathrm{YrA}$ & اثر كروه & كلسيم (mg/dL) \\
\hline$+11 \cdot p$ & r/Trq & . MPr & ثعامل كروهزمان & \\
\hline - /199r & $.1+19$ & V/AT. & اثر زمان & \\
\hline$\cdot / M$ & - & ए人)/AFV & اثر كروه & آهن (ug/dL) \\
\hline.$/ 010$ & .MrA & $\mathrm{rIT/A19}$ & تعامل كروهزمان & \\
\hline$+/ \Delta \wedge \Delta$ & $\cdot \pi+f$ & ( & اثر زمان & \\
\hline$\cdot / 1 \cdot v$ & $r / r+r$ & $\cdot M r V$ & اثر كروه & فسفر (mg/dl) \\
\hline$\cdot / M^{m 9}$ & . Rert & $.1 \cdot p q$ & تعامل كروهزمان & \\
\hline
\end{tabular}

جدول I. مقايسه تغييرات در متثيرها با توجه به تى زوجى

\begin{tabular}{|c|c|c|c|c|}
\hline \multicolumn{4}{|c|}{ ميانكين+|نحراف معيار } & \multirow[t]{2}{*}{ مثغير } \\
\hline ارزش P درون كروهى & يس آزمون & ييشأزمون & كزوه & \\
\hline $.1+1 r^{\circ}$ &.$/ + \pm M T / \cdot \Delta$ & $\cdot / \pm \pm r \Delta /+\Delta$ & تمرين & \multirow{4}{*}{ ضاكسايشى ظرفيت ثام } \\
\hline$\cdot 1 \cdot \cdot 1^{*}$ & $\cdot 1 \cdot \pm m / \cdot \Delta$ & $\cdot 1 \cdot \pm \| V \mid \cdot c$ & مكمل & \\
\hline $.1+\cdot 1^{*}$ & $\cdot 1 \cdot \pm m / \cdot r$ & $. / 1 \pm r e 1 \cdot 8$ & تمرين با مكمل & \\
\hline$+/ 4 q$ & 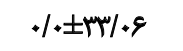 & $\cdot / + \pm M T / \cdot \Delta$ & كتترل & \\
\hline $.1 .49^{\circ}$ & $\vartheta / \pm r \varepsilon / \& \Delta$ & $q \cdot \pm r / f q$ & ت تمرين & \multirow{4}{*}{ كلسيم (mg/dL) } \\
\hline$\cdot \% \cdot r *$ & $N \cdot \pm W / r E$ & V.ArNT & مكمل & \\
\hline $.1++1^{*}$ & $\vartheta / \pm \& / \Re \wedge$ & $V \cdot \pm f \varepsilon / m+$ & تمرين با مكمل & \\
\hline.$/ N F$ & $V \cdot \pm I r / r A$ & $V \cdot \pm 10 / P V$ & كثترل & \\
\hline$\cdot|\Delta Y|$ & $q M / Y q \pm A V M W$ & AVTrIMTA & تمرين & \multirow{4}{*}{ آهن (ug/dL) } \\
\hline - / rva & $Q \Delta / F) \pm R T / M$ & $M / r \cdot \pm \Delta \Delta / q q$ & مكمل & \\
\hline - Mar & $N E M T W M$ & 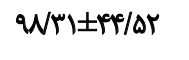 & تمرين با هكمل & \\
\hline.$/ 994$ & $1 \cdot * / r \cdot \pm A T / T$ & $1 . . / M P \pm$ MAY & كنترل & \\
\hline 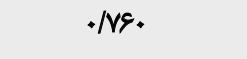 & $\mathrm{r} / \pm A V / F$ & m. tar/er & تمرين & \multirow{4}{*}{ فسفر (mg/dl) } \\
\hline - IDEV & $\varphi / . \pm r v / \Delta$ & fl. \pm mr/ar & مكمل & \\
\hline - IOEV & $\varphi / \pm r^{m} / / \varphi_{r}$ & $\cdot / P \pm r P / \Delta$ & تمرين با مكمل & \\
\hline .1 .84 & $m / . \pm q \cdot / p q$ & $. / f \pm \ldots / f e$ & كنترل & \\
\hline
\end{tabular}


اكسايشى مشاهده نكردند كه بانتايج مطالعه حاضر ناهمسو است.

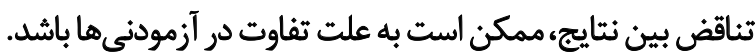

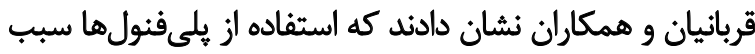

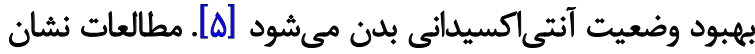

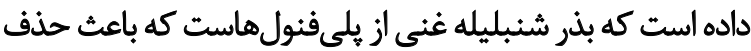

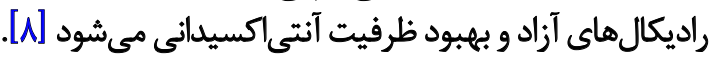

اثرات آنتىاكسيدانى شنبليله در مطالعه جنت و ورمات هماران

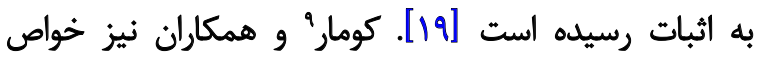

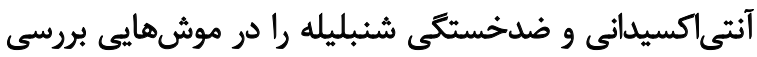

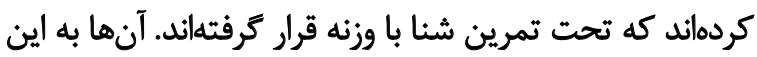

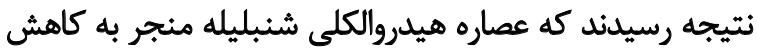

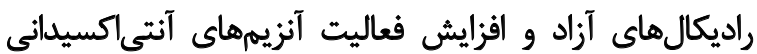

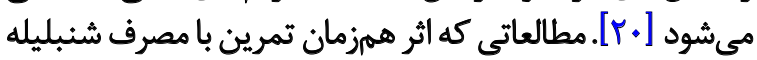
رابر تغييرات آنتىاكسيدان بررسى كردهاند، اندى هستئندان ارشدى و همكاران افزايش ظرفيت تام ضداكسايشى را در

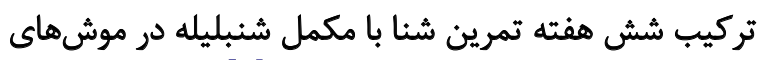

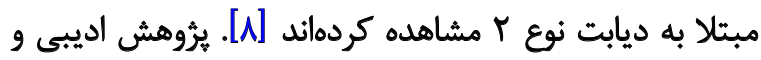

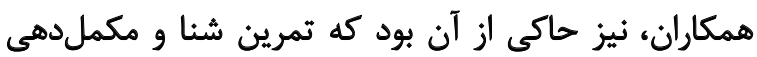

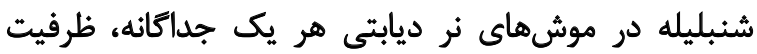

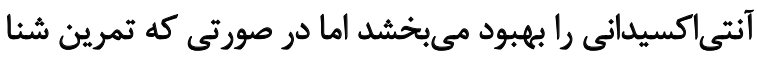

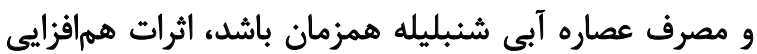

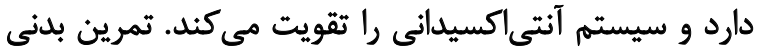

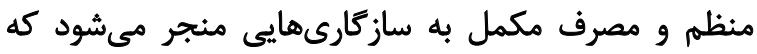

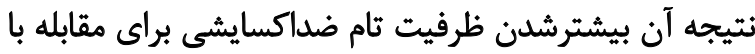

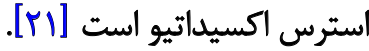

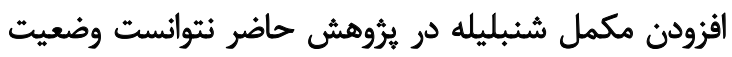

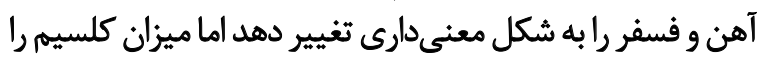

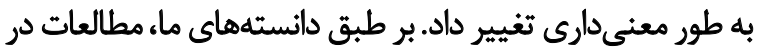

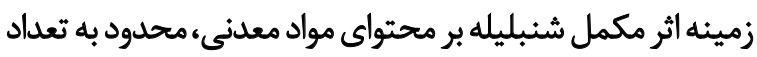

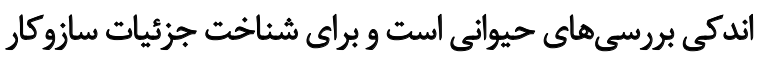

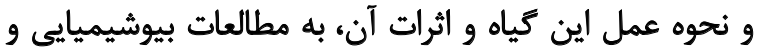

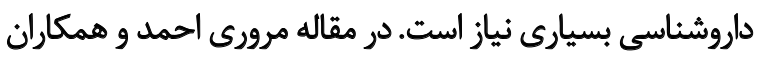

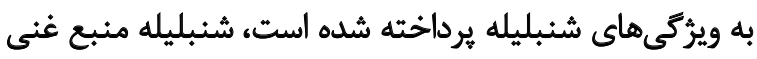

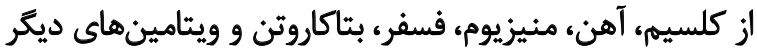

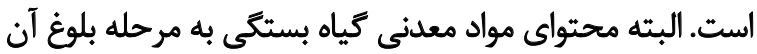

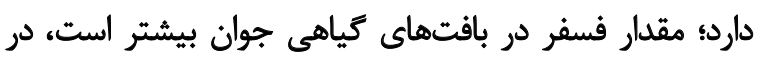

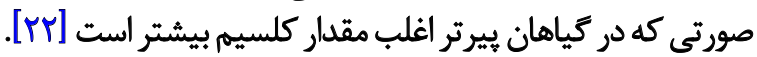
در يك مطالعه، در موشهاى تغذيهشده با بيسكويت تهيهشده

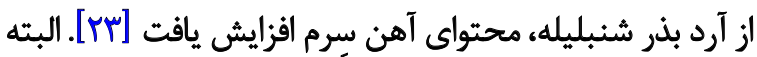

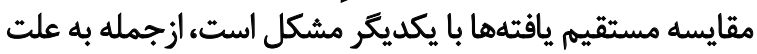
طراحى متفاوت يثوهشها، مقدار املاح كوناكون و مجموعه يكانه

\section{ب0}

مطالعه حاضر با هدف تعيين تأثير مصرف مكمل شنبليله،

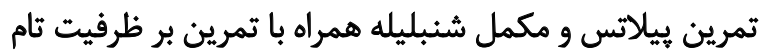

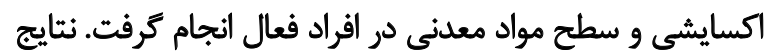

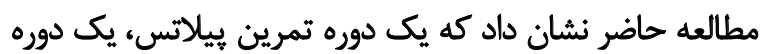

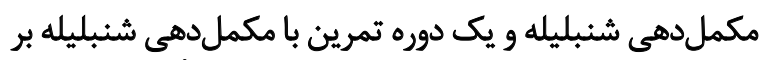
تغييرات ظرفيت تام ضداكسايشى در زنان فعال تأثير معنى دارى دارد و به افزايش ظرفيث آنتى اكسيدانى منجر مى شودان

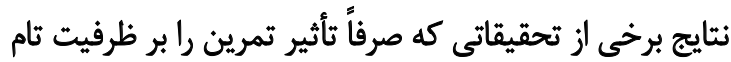

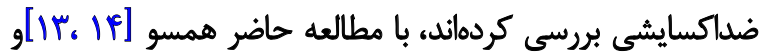

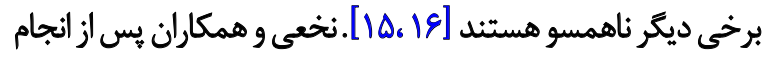

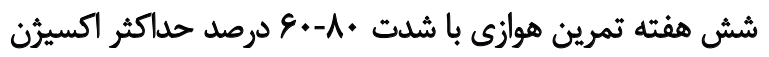

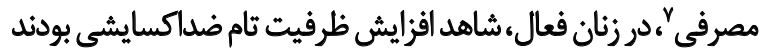

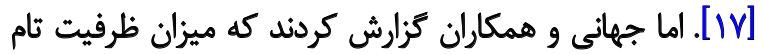

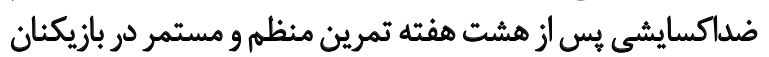

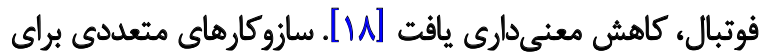

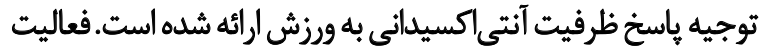

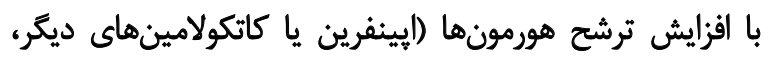

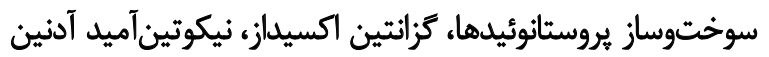

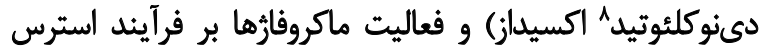

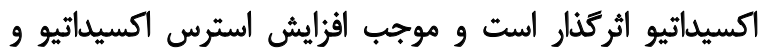

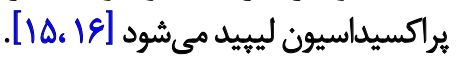

برخى ديكر از بررسىها نيز نشان ميدهد كه در زمان فعاليت

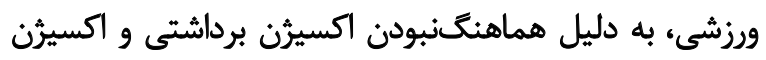

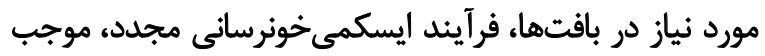

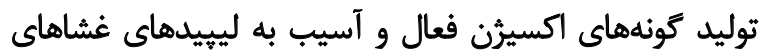

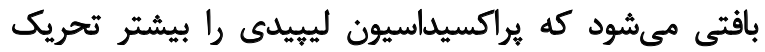

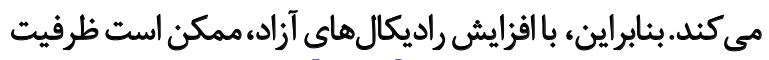

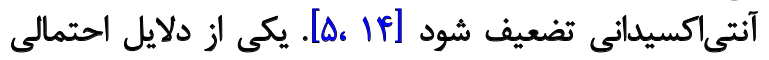

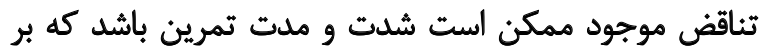

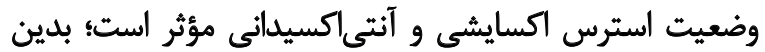

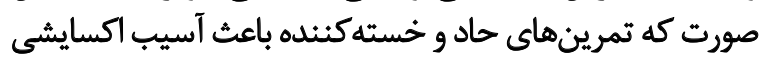

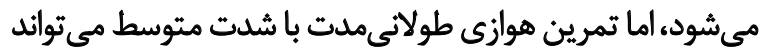

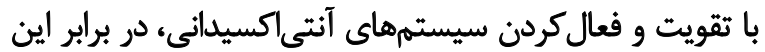
[آسيب، اثر حفاظتى داشته باشد [هائ]

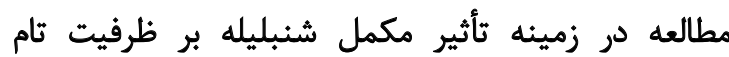

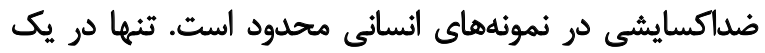

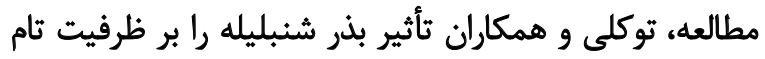

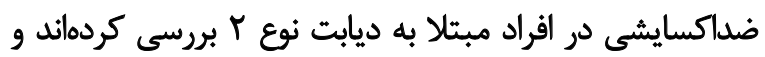

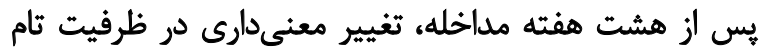


كوجك در بدنٍ نظير آدنوزين ترى فسفات ها، قندها و اسيدهاى

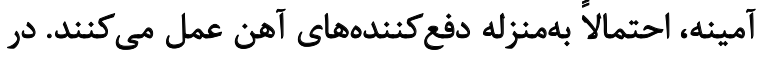

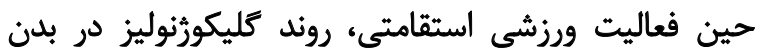

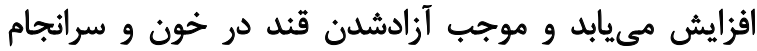

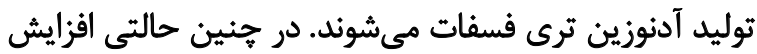

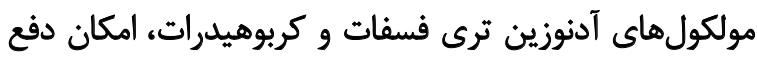

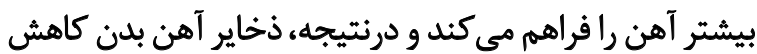

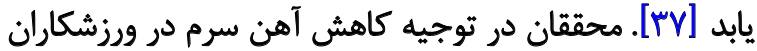

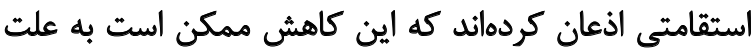

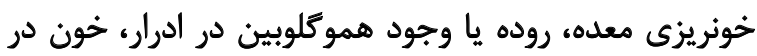

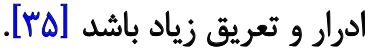
از آنجا كه اين تحقيقات روى افراد ورزشكار صورت كرفته،

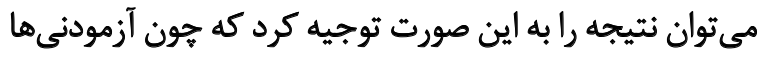

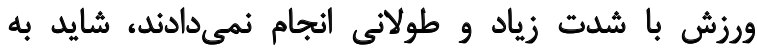

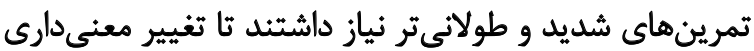

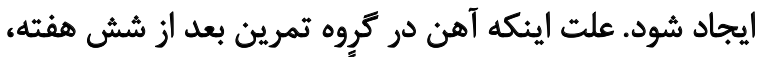

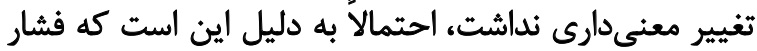

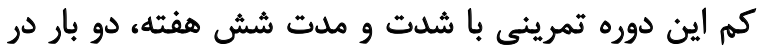

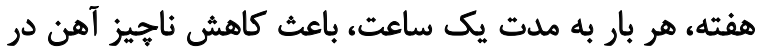

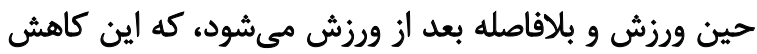

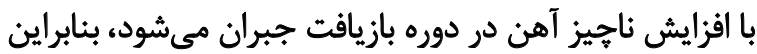
تغييرات آهن معنى ناجيز آنشن در دره باست.

\section{ت نتيجليَّيرى}

در حالت كلى با توجه به تحقيقاتى كه قبلاً خوانده شده

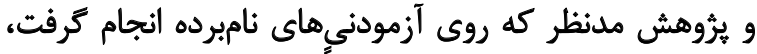

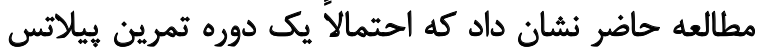

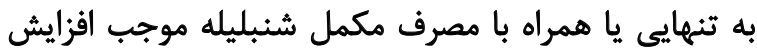

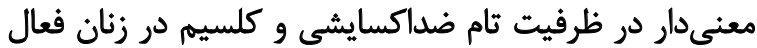

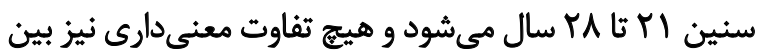

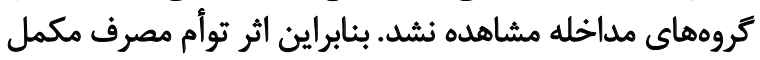

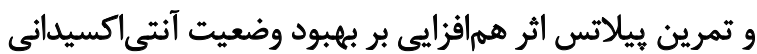

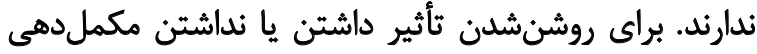

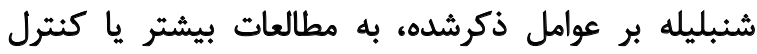

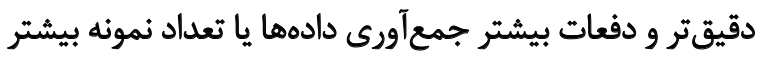
يا دز متفاوت شنبليله نياز است.

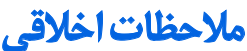

\section{بيروى أز اصول الخلاق يُوهشي}

مطالعه حاضر در كميته اخلاق معاونت يثوهشى دانشكاه

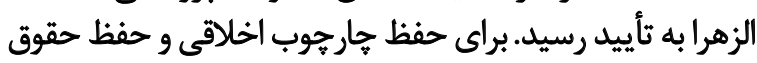

غذايى حامل آنها و يا به اين علت كه در اين مطالعات، در

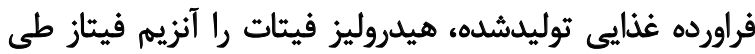

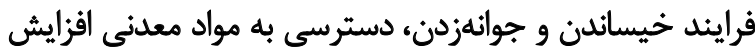

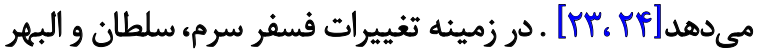

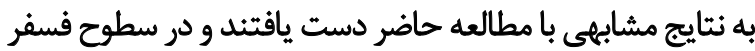

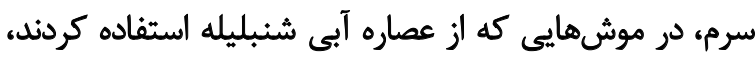

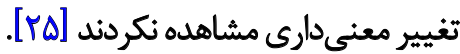

مطالعه حاضر نشان داد يك دوره تمرين هوازى موجب افزايش

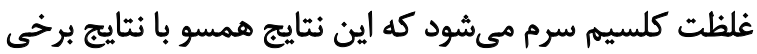

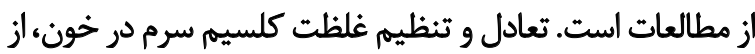

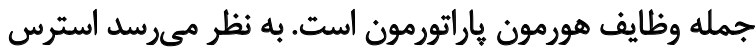

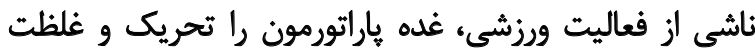

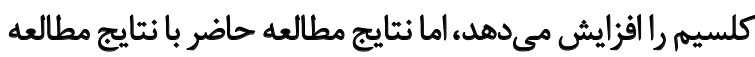

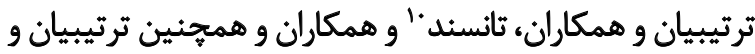

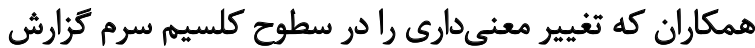

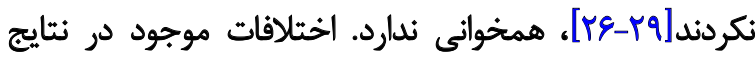

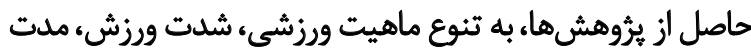

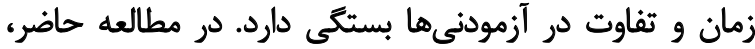

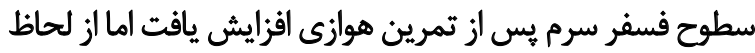
آمارى اين افزايش معنى دار نبود.

نتايج مطالعه معظمى و همكاران حاكى از آن بود كه سطح

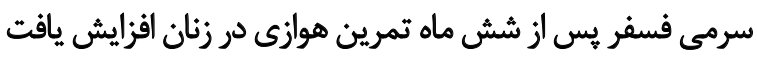

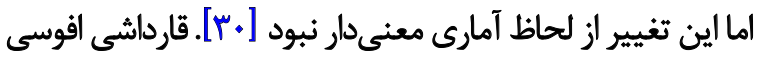

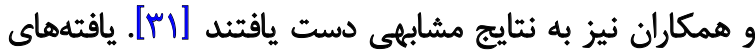

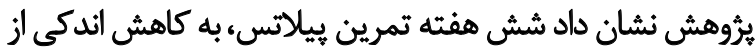

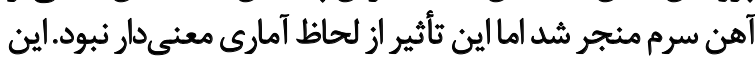

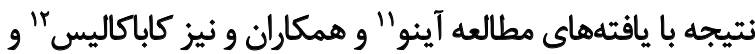

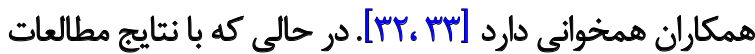

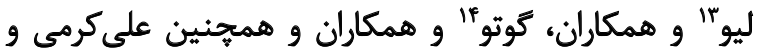

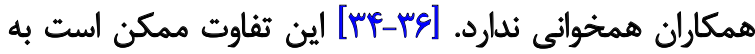

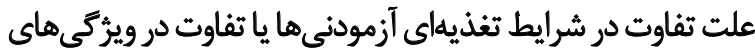

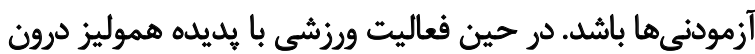

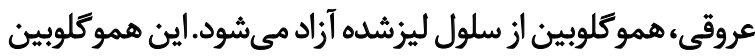

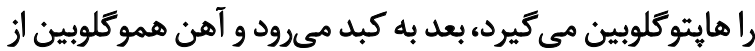

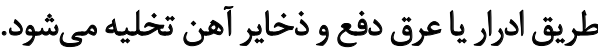

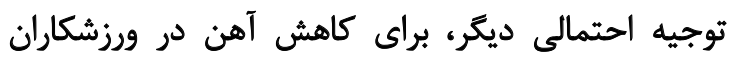
استقامتى، كاهش جذب آهن است. تعداد زيادى از مولكول هاي دري

\section{Townsend}

11. Inoue

12. Kabasakalis

13. Liu

14. Goto 
آزمودنى ها، محقق از برنامه هلسينكى استفاده كرد.

$$
\text { مامى مالى }
$$

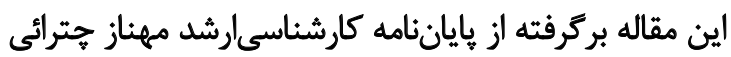

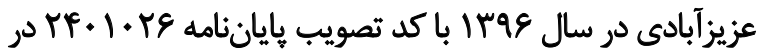

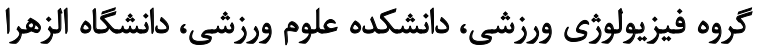

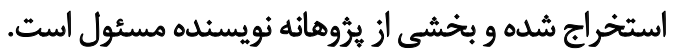

$$
\text { مشاركت نويسندكّان }
$$

تمام نويسئدكان در آمادهسازى اين مقاله مشاركت داشتهاند.

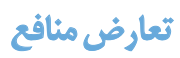

هيجّ گونه تعارض منافعى گزارش نشد. 


\section{References}

[1] Baghaiee B, Nakhostin-Roohi B, Siahkuhian M, Bolboli L. [Effect of oxidative stress and exercise-induced adaptations (Persian)]. Journal of Gorgan University of Medical Sciences. 2015; 17(2):1-15.

[2] Trapp D, Knez W, Sinclair W. Could a vegetarian diet reduce exerciseinduced oxidative stress? A review of the literature. Journal of Sports Sciences. 2010; 28(12):1261-8. [DOI:10.1080/02640414.2010.507676 ] [PMID]

[3] Harasym J, Oledzki R. Effect of fruit and vegetable antioxidants on total antioxidant capacity of blood plasma. Nutrition. 2014; 30(5):511-7. [DOI:10.1016/j.nut.2013.08.019] [PMID]

[4] Sari-Sarraf V, Amirsasan R, Zolfi HR. [Effects of aerobic and exhaustive exercise on salivary and serum total antioxidant capacity and lipid peroxidation indicators in sedentary men (Persian)]. Feyz. 2016; 20(5):427-34.

[5] Ghorbanian B, Mohammadi H, Azali K. [Effects of 10-weeks aerobic training with Rhus coriaria. L supplementation on $\mathrm{TAC}$, insulin resistance and anthropometric indices in women with type 2 diabetes (Persian)]. CMJA. 2017; 7(1):1805-15.

[6] Eyigor S, Karapolat H, Yesil H, Uslu R, Durmaz B. Effects of pilates exercises on functional capacity, flexibility, fatigue, depression and quality of life in female breast cancer patients: A randomized controlled study. European Journal of Physical and Rehabilitation Medicine. 2010; 46(4):481-7. [PMID]

[7] Mohammadzadeh A, Gol A, Oloumi H. [The effects of fenugreek seed powder on oxidant and antioxidant factors in male rats with acetaminophen-induced liver toxicity (Persian)]. Journal of Babol University of Medical Sciences. 2015; 17(9):44-51

[8] Arshadi S, Bakhtiyari S, Haghani K, Valizadeh A. Effects of fenugreek seed extract and swimming endurance training on plasma glucose and cardiac antioxidant enzymes activity in Streptozotocin-induced diabetic rats. Osong Public Health and Research Perspectives. 2015; 6(2):87-93. [DOI:10.1016/j.phrp.2014.12.007] [PMID] [PMCID]

[9] Meghwal M, Goswami TK. A review on the functional properties, nutritional content, medicinal utilization and potential application of fenugreek. Journal of Food Processing and Technology. 2012; 3(9):1-10. [DOI:10.4172/2157-7110.1000181]

[10] Herbold NH, Viscontu BK, Frates S, Bandini L. Tradition and non-traditional supplement use in collegiate female varsity athletes. International Journal of Sport Nutrition and Exercise Metabolism. 2004; 14(5):586-93. [DOI:10.1123/ijsnem.14.5.586]

[11] Peeri M, Yazdanshenasan Shahraki S, Azarbayjani MA, Arshadi S. The effect of endurance training and extract of fenugreek seed on serum Visfatin and Vaspin levels in diabetic rats. Annals of Biological Research. 2013; 4(5):301-6.

[12] El-Nawasany SAE, Shalaby SI, Badria FAE, Magraby GM, Gupta N. Diuretic effect of Fenugreek (Trigonella foenumgraecum Linn) in cirrhotic ascetic patients. Journal of Pharmacognosy and Phytochemistry. 2017; 6(3):185-9.

[13] Babaei P, Rahmani-nia F, Nakhostin B, Bohlooli SH. The effect of VC on immunoendocrine and oxidative stress responses to exercise. Journal of Clinical and Diagnostic Research. 2009; (3):1627-32.

[14] Pilch W, Szygula Z, Tyka AK, Palka T, Tyka A, Cison T, et al. Disturbances in pro-oxidant-antioxidant balance after passive body overheating and after exercise in elevated ambient temperatures in athletes and untrained men. PLOS One. 2014; 9(1):e85320. [DOI:10.1371/journal. pone.0085320] [PMID] [PMCID]
[15] Azizbeigi K, Azarbayjani MA, Atashak S, Stannard SR. Effect of moderate and high resistance training intensity on indices of inflammatory and oxidative stress. Research in Sports Medicine. 2015; 23(1):73-87. [DOI:1 0.1080/15438627.2014.975807] [PMID]

[16] Afzalpour ME, Gharakhanlou R, Gaeini AA, Mohebi H, Hedayati SM. [The effects of vigorous and moderate aerobic exercise on the serum aryl esterase activity and total antioxidant capacity in non-active healthy men (Persian)]. Journal of Sports Science. 2006; 3(9):105-23.

[17] Nakhaee H, Nazarali P, Hanachi P, Hedayati M. [The effect of aerobic training and Cinnamon Zeylanicum intake on total antioxidant capacity in active women (Persian)]. The Horizon of Medical Sciences. 2018; 24(2):88-95.

[18] Jahani G, Firoozrai M, Matin Homaee H, Tarverdizadeh B, Azarbayjani MA, Movaseghi GH, et al. [The effect of continuous and regular exercise on erytrocyte antioxidative enzymes activity and stress oxidative in young soccer players (Persian)]. Razi Journal of Medical Sciences. 2010 17(74):22-32.

[19] Genet S, Kale RK, Baquer NZ. Alterations in antioxidant enzymes and oxidative damage in experimental diabetic rat tissues: Effect of vanadate and fenugreek (Trigonellafoenum graecum). Molecular and Cellular Biochemistry. 2002; 236(1-2):7-12. [DOI:10.1023/A:1016103131408] [PMID]

[20] Kumar GP, Anand T, Singsit D, Khanum F, Anilakumar KR. Evaluation of antioxidant and anti-fatigue properties of Trigonella Foenum-Graecum L. in rats subjected to weight loaded forced swim test. Pharmacognosy Journal. 2013; 5(2):66-71. [DOI:10.1016/j.phcgj.2013.03.005]

[21] Adibi s, Azarbayjani MA, Peeri M. [Effects of endurance training and supplementation of fenugreek seed aqueous extract on plasma antioxidants in male diabetic rats (Persian)]. Physiology of Exercise and Physical Activity. 2013; 6(1):811-20.

[22] Ahmad A, Alghamdi SS, Mahmood K, Afzal H. Fenugreek a multipurpose crop: Potentialities and improvements. Saudi Journal of Biologica Sciences. 2016; 23(2):300-10. [DOI:10.1016/j.sjbs.2015.09.015] [PMID] [PMCID]

[23] Ibrahium MI, Hegazy Al. Iron bioavailability of wheat biscuit supplemented by fenugreek seed flour. World Journal of Agricultural Sciences. 2009; 5(6):769-76

[24] Wani SA, Kumar P. Fenugreek: A review on its nutraceutical properties and utilization in various food products. Journal of the Saudi Society of Agricultural Sciences. 2018; 17(2):97-106. [DOI:10.1016/j.jssas.2016.01.007]

[25] Al-Sultan SI, El-Bahr SM. Effect of aqueous extract of fenugreek (Trigonella Foenum-Graecum L) on selected biochemical and oxidative stress biomarkers in rats intoxicated with carbon tetrachloride. International Journal of Pharmacology. 2015; 11(1):43-9. [DOI:10.3923/ ijp.2015.43.49]

[26] Alghadir AH, Aly FA, Gabr SA. Effect of moderate aerobic training on bone metabolism indices among adult humans. Pakistan Journal of Medical Sciences. 2014, 30(4):840-4. [DOI:10.12669/pjms.304.4624]

[27] Townsend R, Elliott-Sale KJ, Pinto AJ, Thomas C, Scott JPR, Currell K, et al. Parathyroid hormone secretion is controlled by both lonised calcium and phosphate during exercise and recovery in men. The Journal of Clinical Endocrinology \& Metabolism. 2016; 101(8):3231-9. [DOI:10.1210/ jc.2016-1848] [PMID]

[28] Tartibian B, Sheikhlou Z, Malandish A, Rahmati-Yamchi M, Afsar Garebag $R$. [Effect of moderate-intensity aerobic training on alkaline phosphatase gene expression and serum markers of bone turnover in sed- 
entary postmenopausal women (Persian)]. Tehran University Medical Journal. 2017; 74(10):723-34.

[29] Tartibian B, Motabsaee N, Tolouei-Azar J. The influence of nine- week intensive aerobic exercises, calcium and vitamin $D$ supplementation on the metabolic response of bone formation biomarkers in young women. Zahedan Journal of Research in Medical Sciences. 2013; 15(2):47-54.

[30] Moazami M, Jamali FS. [The effect of 6-months aerobic exercises on bone-specific alkaline phosphatase and parathyroid hormone in obese inactive woman (Persian)]. The Iranian Journal of Obstetrics, Gynecology and Infertility. 2013; 5(10):71-9.

[31] Ghardashi Afousi AR, Khashayar P, Gaeni AA, Choobineh S, Fallahi AA, Javidi $M$. [Effect of high intensity interval training on hormonal factor affecting bone metabolism (Persian)]. Razi Journal of Medical Sciences. 2015; 22(130):29-37.

[32] Inoue Y, Matsui A, Asai Y, Aoki F, Matsudi T, Yano H. Effect of exercise on iron metabolism in horses. Biological Trace Element Research. 2005; 107(1):33-42. [DOI:10.1385/BTER:107:1:033]

[33] Kabasakalis A, Kalitsis K, Nikolaidis MG, Tsalis G, Kouretas D, Loupos $D$, et al. Redox, iron, and nutritional status of children during swimming training. Journal of Science and Medicine in Sport. 2009; 12(6):691-6. [DOI:10.1016/j.jsams.2008.05.005] [PMID]

[34] Liu YQ, Duan XL, Chang YZ, Wang HT, Qian ZM. Molecular analysis of increased iron status in moderately exercised rats. Molecular and Cellular Biochemistry. 2006; 282(1-2):117-23. [DOI:10.1007/s11010-0061522-4] [PMID]

[35] Goto K, Sumi D, Kojima C, Ishibashi A. Post-exercise serum hepcidin levels were unaffected by hypoxic exposure during prolonged exercise sessions. PLOS One. 2017; 12(8):e0183629. [DOI:10.1371/journal. pone.0183629] [PMID] [PMCID]

[36] Alikarami H, Nikbakht M, Valipour Dehnou V, Ghalavand A. [Effect of 8 weeks of continuous moderate intensity aerobic training on iron status in club-level football players (Persian)[. Horizon of Medical Sciences. 2017; 23(2):129-33. [DOI:10.18869/acadpub.hms.23.2.129]

[37] Ramezanpour MR, Kazemi M. [Effects of aerobic training along with iron supplementation on the hemoglobin, red blood cells, hematocrit, serum ferritin, transferrin and iron in young girls (Persian)]. Koomesh. 2012; 13(2):233-9. 